\section{Direct Demonstration of the Mutagenic Action of Euflavine on Baker's Yeast}

It has been shown in a series of recent papers ${ }^{1-3}$ that baker's yeust grown in the presence of acriflavine undergoes a profound modification. After a few generations of growth in the presence of the dye, the culture is found to be composed almost exclusively of cells which are deficient in some respiratory enzymes (cytochrome oxidase, succinic dehydrogenase) and which are consequently unable to oxidize glucose. Cells presenting these characteristics have been isolated in pure cultures which have been maintained in normal medium for several years. Their respiratory deficiency has proved to be permanent.

Although similar mutant cells arise spontaneously with a rather high frequency under normal cultural conditions, we have claimed, on the basis of a quantitative study, that the described predominance of mutant cells in cultures grown in the presence of acriflavine is due not to a selective but to a mutagenic action of the dye

This conclusion has now been subjected to a direct test. Single cells from a normal culture of Saccharomyces cerevisioe (diploid strain B-II) are placed with the help of a micromanipulator in the microdissection chamber in a droplet of culture medium containing $10^{-8}$ parts of 2-8 diamino 10 methyl acridinium chloride (purified euflavine) ${ }^{5}$. The budding of these cells is observed under the microscope, the light beam being filtered through a cuvette $(30 \mathrm{~mm}$.) containing a concentrated solution of acriflavine. The successive daughter cells $(a, b, c, d$, etc., in the diagram) are detached from the mother cell $(M)$ as they form, rinsed and removed to a droplet of normal medium. The mother cell, on the other hand, is either left in the drop of euflavine or transferred to a fresh drop of the same medium kept up to this time in the dark. Similarly, one second-generation bud is isolated from each of the daughter cells. Finally,

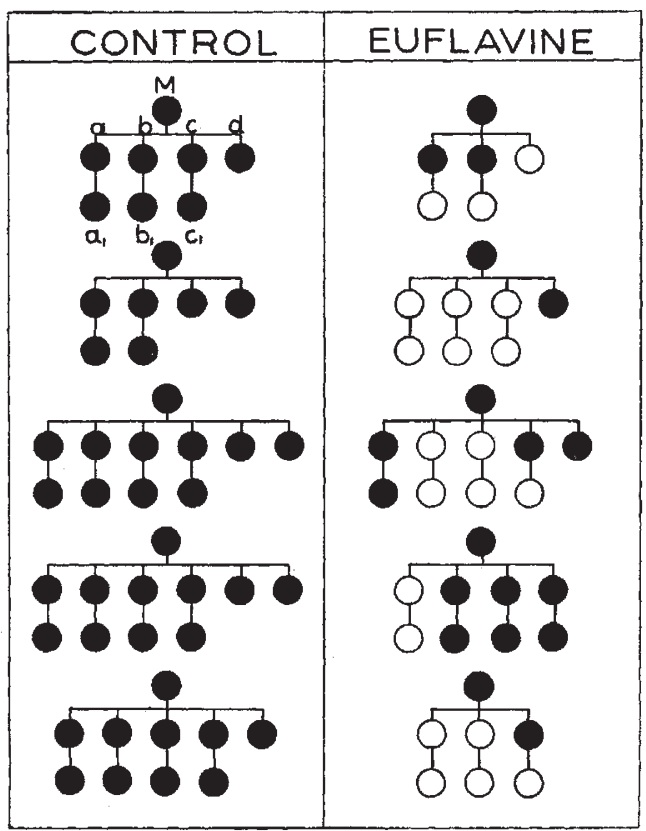

Descendants of isolated yeast cells proliferating in the presence or absence of euflavine. Black circles, normal cells; white circles,
mutant cells at the end of the experiment, the mother cell itself is transferred to normal medium.

Similar isolations are performed in the absence of euflavine to provide controls.

After the isolated cells have formed sizable clones, the latter are transferred from the microdissection chamber on to normal medium. Thus stock cultures are established, which can be subjected to the Nadi reaction for indophenoloxidase, this reaction serving as a criterion of the normal or mutant character of the clones ${ }^{3}$.

The diagram gives the results of five such experiments and their controls in the form of 'pedigrees'. It can be seen that among 42 descendants of the 5 control cells no spontaneous mutants were found. Among 35 descendants of the 5 cells placed in euflavine, 21 gave rise to mutant clones. Since the experimental arrangement offers no opportunity for selection (aside from cell mortality which was zero), the muta. genic action of acridines is unequivocally confirmed by these experiments.

Consideration of the cell lineages shown in the diagram seems to warrant the following deductions concerning the nature of the mutation process. We notice that in the experiment all mother cells, after producing several mutant buds, remained capable of producing some normal ones and, in any event, remained normal themselves. This makes the hypothesis of a gene mutation, or of a mutation of any cell constituent for that matter, very unlikely. The appearance of mutant cells as a consequence of the euflavine treatment is best accounted for by assuming that an auto-reproducing cytoplasmic component, necessary for the synthesis of the respiratory enzymes in question, has not been included in some of the buds. Since a cell can alternately produce mutant and normal buds, this cytoplasmic component must be ascribed a particulate nature. All these conelusions conform with and reinforce those previously drawn from the quantitative study of the action of acriflavine and from the results of the crosses between normal and mutant cells ${ }^{4,6}$.

Institut de Génétique du C.N.R.S.

Boris EpHrussi HELENe HotTinguer and

Institut de Biologie physico-chimique, Paris. July 26.

${ }^{1}$ Ephrussi, B., Hottinguer, H., and Chimènes, A. M., Ann. Inst. Pasteur, 76, 351 (1949)

${ }^{2}$ Slonimski, P. P., Ann. Inst. Pasteur, 76, 510 (1949).

a Slonimski, P. P., and Ephrussi, B., Ann. Inst. Pasteur, 77, 47 (1949).

- Ephrussi, B., L'Héritier, Ph., and Hottinguer, H., Ann. Inst. Pasteur, 77, 64 (1949)

' This compound, kindly given to us by Prof. Adrien Albert, has been found to be particularly active (Marcovich, H., unpublished).

- Ephrussi, B. Hottinguer, H., and Tavlitzki, J., Ann. Inst. Pasteur, 76,419 (1949).

\section{Search for Linkage between Genes determining a Vitamin Requirement}

WHETHER genes are distributed at random between and along the chromosomes, or show some systematic arrangement related to their function in the biochemistry and morphogenesis of the organism, has long been a crucial problem in genetics ${ }^{1-4}$. The location of genes in relation to their detectable effects in organisms as varied as maize, Drosophila, the mouse, man and Neurospora suggests that "if such a distribution [non-random] exists it does not leap to the eye"s. However, there have been enough 